- Implants and teeth have differential mobility and support.

- Fixed prostheses supported by implants and teeth suffer more implant failure.

- When implants and teeth are connected there is a phenomenon of tooth intrusion.

- An understanding of these points will aid in treatment planning.

\title{
Connecting implants to teeth
}

\author{
W. Chee ${ }^{1}$ and S. Jivraj ${ }^{2}$
}

\begin{abstract}
Osseointegrated implants have proven to have a high degree of success in the edentulous arches. ${ }^{1}$ This success has been replicated in partially edentulous arches. ${ }^{2-7}$ When natural teeth are present, it can be tempting to fabricate restorations using support from both implants and natural teeth. The mechanism of attachment and the perceived problem of the differential support provided by the implant and the tooth have been discussed by many authors. ${ }^{8-13}$
\end{abstract}

\begin{tabular}{|c|}
\hline IMPLANTS \\
\hline 1. Rationale for dental implants \\
\hline $\begin{array}{l}\text { 2. Treatment planning of implants in } \\
\text { posterior quadrants }\end{array}$ \\
\hline $\begin{array}{l}\text { 3. Treatment planning of implants in } \\
\text { the aesthetic zone }\end{array}$ \\
\hline $\begin{array}{l}\text { 4. Surgical guidelines for dental } \\
\text { implant placement }\end{array}$ \\
\hline $\begin{array}{l}\text { 5. Immediate implant placement: } \\
\text { treatment planning and surgical steps } \\
\text { for successful outcomes }\end{array}$ \\
\hline $\begin{array}{l}\text { 6. Treatment planning of the } \\
\text { edentulous maxilla }\end{array}$ \\
\hline $\begin{array}{l}\text { 7. Treatment planning of the } \\
\text { edentulous mandible }\end{array}$ \\
\hline $\begin{array}{l}\text { 8. Impressions techniques for implant } \\
\text { dentistry }\end{array}$ \\
\hline $\begin{array}{l}\text { 9. Screw versus cemented implant } \\
\text { supported restorations }\end{array}$ \\
\hline $\begin{array}{l}\text { 10. Designing abutments for } \\
\text { cement retained implant supported } \\
\text { restorations }\end{array}$ \\
\hline 11. Connecting implants to teeth \\
\hline $\begin{array}{l}\text { 12. Transitioning a patient from teeth } \\
\text { to implants }\end{array}$ \\
\hline $\begin{array}{l}\text { 13. The role of orthodontics in implant } \\
\text { dentistry }\end{array}$ \\
\hline $\begin{array}{l}\text { 14. Interdisciplinary approach to } \\
\text { implant dentistry }\end{array}$ \\
\hline $\begin{array}{l}\text { 15. Factors that affect individual } \\
\text { tooth prognosis and choices in } \\
\text { contemporary treatment planning }\end{array}$ \\
\hline 16. Maintenance and failures \\
\hline
\end{tabular}

Connecting teeth to osseointegrated implants presents a biomechanical challenge. This is due to the implant being rigidly fixed to the bone and the tooth being attached to the bone with a periodontal ligament. This ligament allows teeth more mobility than osseointegrated implants. Studies have been equivocal about the efficacy of this connection. Some studies indicate when there is rigid connection of implants to teeth, that this is an acceptable procedure and restorations survive. ${ }^{12-13}$ Recent studies indicate that restorations with tooth and implant support are not as successful. ${ }^{14-17}$

One manufacturer's approach to the problem has been the inclusion of an 'intra-mobile element' into the implant. This resilient component was to provide flexibility to the implant to

\footnotetext{
1*Ralph W. and Jean L. Bleak Professor of Restorative Dentistry, Director of Implant Dentistry at the University of Southern California School of Dentistry / Private Prosthodontics Practitioner, Pasadena, California; ${ }^{2}$ Chairman, Section of Fixed Prosthodontics and Operative Dentistry, University of Southern California School of Dentistry / Private Prosthodontics Practitioner, Burbank, California

*Correspondence to: Dr Winston Chee, School of Dentistry, Rm. 4374 University Park, University of Southern California, Los Angeles, CA 90089-0641, USA

Email:wchee@usc.edu
}

\section{Refereed Paper}

() British Dental Journal 2006; 201 : 629-632

DOI: $10.1038 /$ sj.bdj.4814260 compensate for the mobility of the tooth. When this system was evaluated for that feature in an in vitro study it was demonstrated that the "intramobile element' did not contribute to the flexibility of the system. Furthermore, bending forces were transmitted to the retaining screw of the implant. ${ }^{10,11}$ Other authors have discussed using a non-rigid connecting system to allow teeth to move independently of the implant while still being connected; key and key way types of connections have been described. When non-rigid connectors are used tooth intrusion has been observed. ${ }^{18-21}$ Possible causes of this intrusion have been assigned to friction between the matrix and patrix of the attachment where occlusal forces depress the tooth and friction between the non-rigid components cause the eventual intrusion of teeth (Figs 1-2). Similarly micro-jamming of food particles at the bottom of the matrix is said to cause a similar intrusion as impaction of particles will prevent the tooth from rebounding to its original position. It has also been postulated that flexion of the mandible could generate forces which cause intrusion of teeth connected to implants. However, intrusion has been documented in the maxillary as well as mandibular arches. ${ }^{21}$ In addition the phenomenon of intrusion has been seen in telescopic connections where no occlusal force is applied to the teeth. ${ }^{22,23}$ Telescopic crowns on remaining natural teeth between implants have been used to incorporate the natural teeth into implant 
Fig. 1 Example of intrusion of tooth when connected to implants with a non-rigid connector.

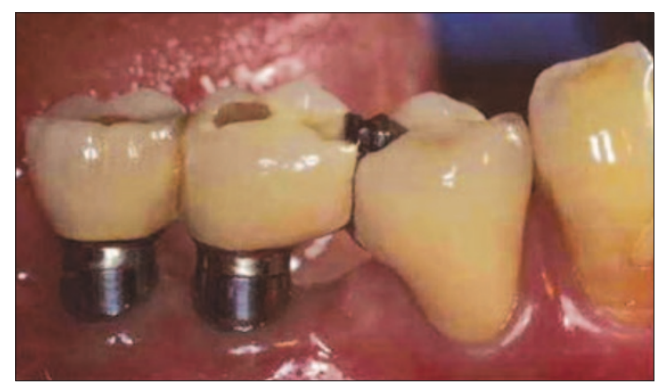

Fig. 2 Another example of intrusion of tooth when connected to implants with non-rigid connector.
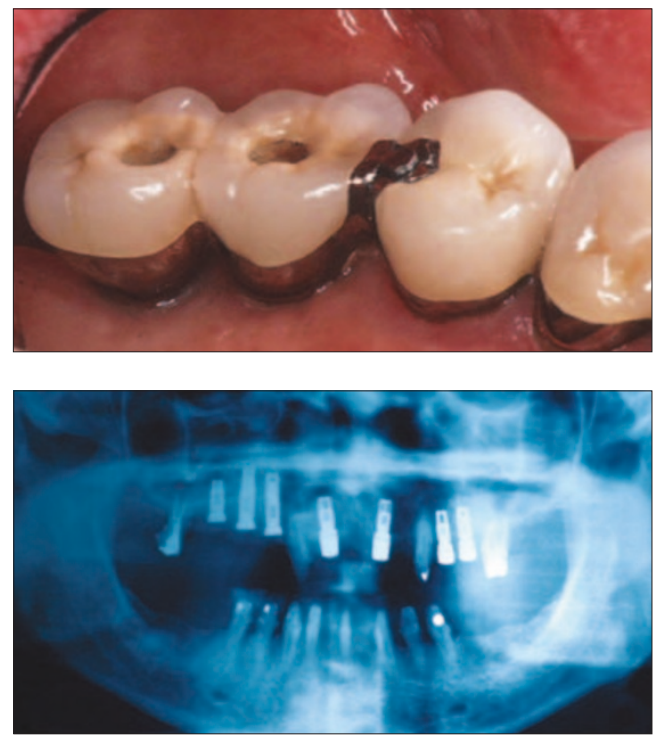

Fig. 3 Panoramic radiograph illustrating implants placed on maxilla, canine teeth were used to support a provisional restoration and were planned for extraction, however the patient refused this and elected to maintain them.
Fig. 4 Intra oral view of telescopic crowns on teeth and implant abutments.

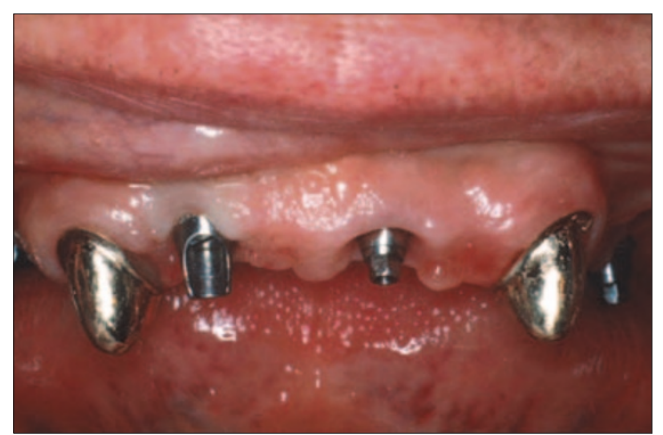

Fig. 5 Intrusion of the tooth with telescopic crown is evident about four months after delivering restorations.
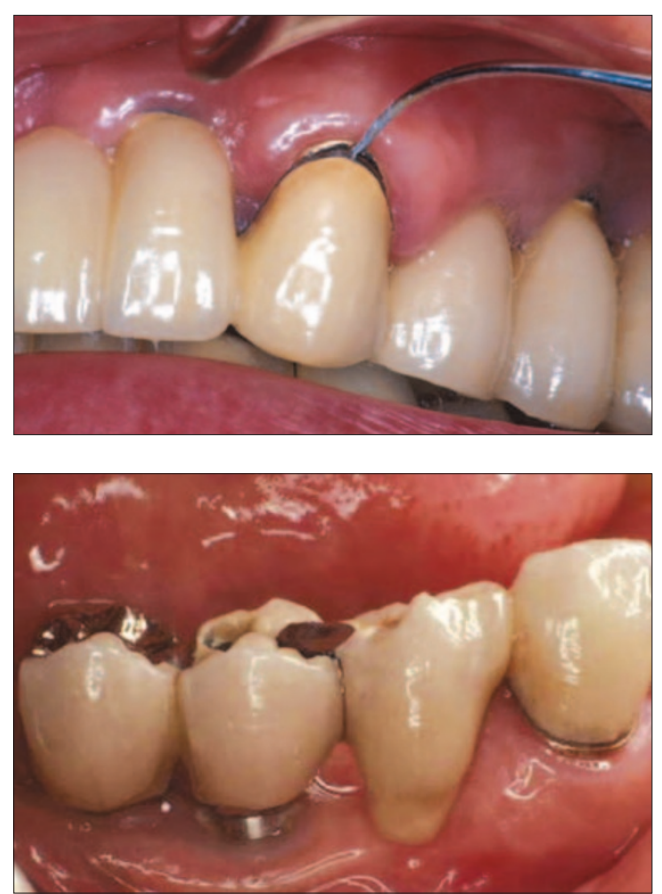

supported restorations. It has been reported that intrusion of natural teeth occurs in these situations as well, even though there is no direct contact of the natural tooth with the opposing occlusion (Figs 3-5). Two theories have been presented to describe this phenomenon. One proposes that the periodontal ligament atrophies due to disuse or lack of stimulation. ${ }^{24-26}$ Another describes the transfer of shock waves to the natural tooth which forces the tooth into the socket. ${ }^{27}$

\section{DISCUSSION}

Rigid connection of teeth to implants is not rational due to the adverse effects to the implants in the long term. Non-rigid connection has the potential of intrusion of teeth. ${ }^{14-17} \mathrm{~A}$ review of the literature will reveal that there are many authors who advocate this tooth-implant connection despite this mis-match of mobility. ${ }^{12,28}$ This connection is used to potentially gain support from the tooth, to preserve the tooth or to provide stability to rotational forces directed at the screw joint of the implant supported part of the restoration.

Clinicians who advocate connecting teeth to implants rigidly accept the differential mobility of the implant and natural tooth. They deem there is sufficient flexibility in the implant stack to allow sharing of the load. ${ }^{28-31}$ For this to occur, the implant components and their retaining screws must exhibit some degree of flexibility, ${ }^{32}$ the periodontal support of the natural tooth must be adequate and constant and the amplitude of movement of the prostheses must be minimal. ${ }^{33}$ This amplitude of movement will also affect the magnitude of the force to the screw joint on the implant and must be less than the preload of the retaining screw in order to prevent screw loosening. Constant bending of the screw could lead to metal fatigue and failure of the implant components. ${ }^{34}$

Others believe that a non-rigid connection placed between the pontic and the tooth will alleviate the biomechanical mis-match of mobility between the implant and tooth. Different methods of this connection have been described..$^{8,9}$ However, when this type of connection occurs the phenomenon of intrusion of the tooth has been reported. ${ }^{14-17,21,23}$

One rational method has been reported that can potentially allow sharing of load between tooth and implant and eliminate the problem of intrusion of teeth. ${ }^{34}$ This technique has been modified and will be described in the following patient presentation.

It was determined that a fixed partial denture was required from implant \#30 (mandibular right first molar), implant \#29 (mandibular right second premolar), pontic \#28 (mandibular right first premolar) and tooth \#27(mandibular right canine). A non rigid connection in the form of a deep removable partial denture (RPD)-type spoon-shaped rest was fabricated on the distal of the pontic; the corresponding rest seat was prepared on the implant \#29 (Fig. 6). The pontic was rigidly connected to the tooth 
(Fig. 7). To allow retrieval of the implant restorations a telescopic crown was placed onto tooth \#27 and the superstructure attached to the pontic was placed over the telescope with a set screw to aid in retention (Fig. 8). This allowed removal of the superstructure from the tooth and removal of the implant segment if required. Mechanically this system allowed loading of the implant and tooth when loads were applied to the pontic and free movement of the tooth when occlusal forces were applied to the tooth alone. No intrusion of the teeth or adverse effects to the abutments have been noted in restorations with this design (Fig. 9).

This design addresses both problems of overloading the implant due to excessive cantilevers and preventing intrusion of teeth when connected to implants. This design also allows load sharing between the two types of support for the prostheses. Figure 10 diagrammatically illustrates how most clinicians connect implants to teeth. In this system if we assume that the implant restoration and pontic segment are rigid, then no load sharing is possible with the tooth, since the tooth has much more mobility than the implant. In addition the tooth can intrude. In effect there is a cantilever to the implant support placing stress on the screw joint and to the implant itself. Figure 11 illustrates a more rational connection of implants and teeth; in this system the tooth-pontic segment can move independently of the rigid implant and occlusal loads on the pontic area can be shared between tooth and implant abutments. Figure 12 is a modification of the idea presented in Figure 11; the attachment is substituted with a deep removable partial denture-like rest which allows more freedom of movement. This is the method used when no choice remains but to connect teeth to implants.

\section{CONCLUSION}

A review of the literature and discussion of the effects of connecting teeth to implants with different modalities has been presented. There is no doubt that the free standing option where teeth are not connected to implants is the preferred method of restoring missing teeth. A method of implementing the connection of teeth to implants has been described and may be of use when the free standing option is excluded.

1. Adell R, Eriksson B, Lekholm U etal. A long term follow up study of osseointegrated implants in the treatment of totally edentulous jaws. Int J Oral Maxillofac Implants 1990; 5: 347-359.

2. Quirynen $M$, Naert I, van Steenberghe $D$, Nys L. A study of 589 consecutive implants supporting complete fixed prostheses. Part I: Periodontal aspects. J Prosthet Dent 1992; 68: 655-663.

3. Naert I, Quirynen $M$, van Steenberghe D, Darius P. A study of 589 consecutive implants supporting complete fixed prostheses. Part II: Prosthetic aspects. J Prosthet Dent 1992; 68: 949-956.

4. Werner L, Thornton B, Reichsthaler J, Schneider B. Statistical analyses on the success potential of osseointegrated implants: A retrospective single dimension statistical analysis. J Prosthet Dent 1993; 69: 176-185.

5. Van Steenberghe D. A retrospective multicenter evaluation of the survival rate of osseointegrated fixtures supporting

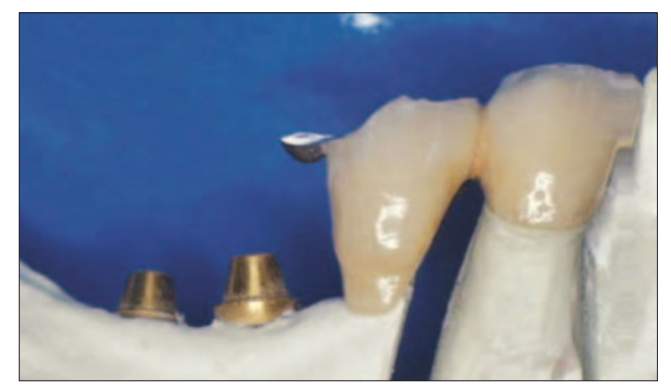

Fig. 7 The case in Figure 6 on the master cast prior to delivery - note the rest attached to the pontic.

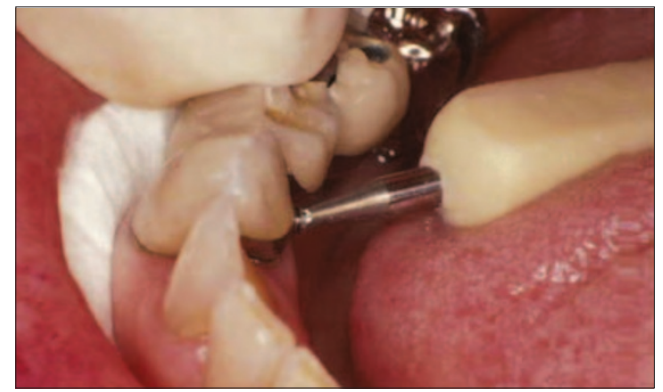

Fig. 8 Intra-oral view of the lingual set screw being tightened on fastening the crown and pontic to the telescopic coping on the tooth.

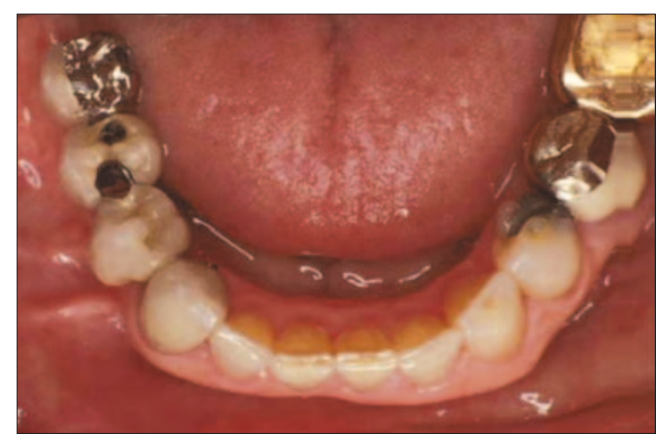

Fig. 9 Occlusal view of restored mandibular arch.

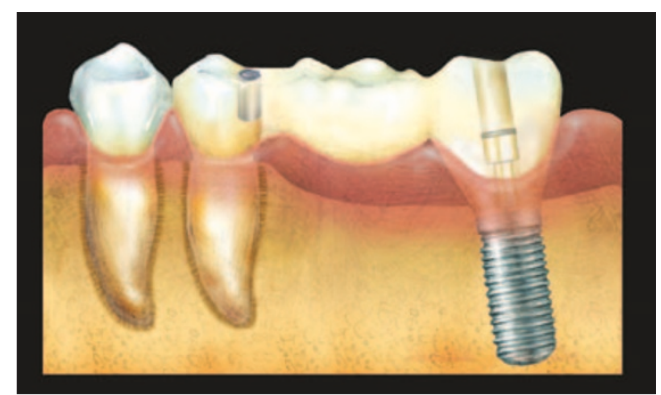

Fig. 10 Diagram of tooth to implant connection with attachment placed between the pontic and the tooth.

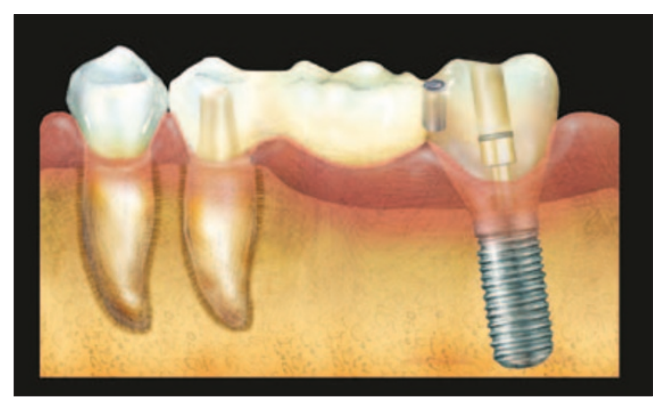

Fig. 11 Diagram of tooth to implant connection with attachment placed between the implant supported restoration and pontic.

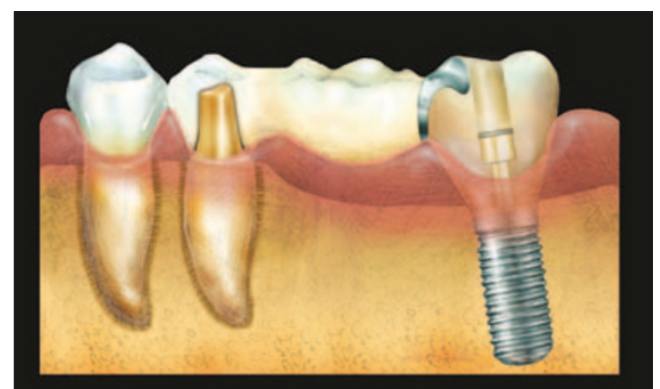

Fig. 12 Diagram of the suggested method of connecting implants to teeth with connection using a deep removable partial denture-type rest with the rest seat on the implant supported restoration. 
fixed partial prostheses in the treatment of partial edentulism. J Prosthet Dent 1989; 61: 217-223.

6. Naert I, Quirynen M, van-Steenberghe D, Darius P. A six-year prosthodontic study of 509 consecutively inserted implants for the treatment of partial edentulism. J Prosthet Dent 1992; 67: 236-245.

7. Pylant T, Triplet R G, Key M C, Brunsvold M A. A retrospective evaluation of endosseous titanium implants in the partially edentulous patient. Int J Oral Maxillofac Implants 1992; 7: 195-202.

8. Sullivan D Y. Prosthetic Considerations for the utilization of osseointegrated fixtures in the partially edentulous arch. Int J Oral Maxillofac Implants 1986; 1: 39-45.

9. Reider CE. Copings on tooth and implant abutments for superstructure prostheses. Int J Periodont Rest Dent 1990; 6: $437-453$.

10. Babbush C A, Kirsch A, Mentag, Hill B. Intramobile Cylinder (IMZ) two stage osteointegrated implant system with the intra mobile element (IME): Part 1. Its rationale and procedure for use. Int J Oral Maxillofac Implants 1987; 2: 203-216.

11. Kay H. Free standing vs. implant - tooth - interconnected restorations: understanding the prosthodontic perspective. Int J Periodont Rest Dent 1993: 13: 47-68.

12. Astrand J, Astrand P, Ahlen K et al. Implants in partially edentulous patients. A longitudinal study of bridges supported by both implants and natural teeth. Clin Oral Implants Res 1992; 3: 49-56.

13. Ericsson I, Lekholm U, Branemark PI, Lindhe J. A clinica evaluation of fixed-bridge restorations supported by the combination of teeth and osseointegrated titanium implants. J Clin Periodonto/ 1986; 13: 307-312.

14. Naert I E, Duyck J A, Hosny M M et al. Freestanding and tooth-implant connected prostheses in the treatment ofpartially edentulous patients Part II: An up to 15-years radiographic evaluation. Clin Oral Implants Res 2001; 12: 245-251.

15. Naert I E, Duyck J A, Hosny M M, Van Steenberghe D. Freestanding and tooth-implant connected prostheses in the treatment of partially edentulous patients. Part I: An up to 15-years clinical evaluation. Clin Oral Implants Res 2001; 12:237-244.

16. Block M S, Lirette D, Gardiner D et al. Prospective evaluation of implants connected to teeth. Int J Oral Maxillofac Implants 2002; 17: 473-487.

17. Bragger U, Karoussis I, Persson R et al.Technical and biological complications/failures with single crowns and fixed partial dentures on implants: a 10-year prospective cohort study. Clin Oral Implants Res 2005; 16: 326-334

18. Garcia L T, Oesterle L J. Naturel tooth intrusion phenomenon with implants: A survey. Int J Oral Maxillofac Implants 1998; 13: 227-231.

19. Schlumberger T L, Bowley J F, Maze G I. Intrusion phenomenon in combination tooth-implant restorations:
A review of the literature. J Prosthet Dent 1998; 80: 199-203.

20. Pesun IJ. Intrusion of teeth in the combination implant-tonatural-tooth fixed partial denture: a review of the theories. J Prosthodont 1997; 6: 268-277.

21. Chee $\mathrm{W} W, \mathrm{Cho} G \mathrm{C}$. A rationale for not connecting implants to natural teeth. J Prosthodont 1997; 6: 7-10.

22. Reider C E. Copings on tooth and implant abutments for superstructure prostheses. Int J Periodont Rest Dent 1990 6: 437-453.

23. Cho G C, Chee W W. Apparent intrusion of natural teeth under an implant-supported prosthesis: a clinical report. JProsthet Dent 1992; 68: 3-5.

24. Pesun I J, Steflik D E, Parr G R, Hanes P J. Histologic evaluation of the periodontium of abutment teeth in combination implant/tooth fixed partial denture. Int J Oral Maxillofac Implants 1999; 14: 342-350.

25. Cohn S A. Disuse atrophy of the periodontium in mice. Arch Oral Biol 1965; 10: 909-919.

26. Cohn S A. Disuse atrophy of the periodontium in mice following partial loss of function. Arch Oral Bio/1966 11: 95-102.

27. Sheets $C$ G, Earthman J C. Natural tooth intrusion and reversal in implant assisted prosthesis: evidence and a hypothesis for the occurrence. J Prosthet Dent 1993; 70: 513-520.

28. Ericsson I, Lekholm U, Branemark PI, Lindhe J. A clinical evaluation of fixed-bridge restorations supported by the combination of teeth and osseointegrated titanium implants. J Clin Periodontol 1986; 13:307-312.

29. Rangert B, Gunne J, Glantz P-O, Svensson A. Vertical load distribution on a three unit prosthesis supported by a natural tooth and a single Branemark implant An in vivo study. Clin Oral Implants Res 1995: 6: 40-46.

30. Lundgren D, Laurell L. Biomechanical aspects of fixed bridgework supported by natural teeth and endosseous implants. Periodontology 2000 1994; 4: 23-40.

31. Rangert B, Gunne J, Sullivan D Y. Mechanical aspects of a Branemark implant connected to a natural tooth: An in vitro study. Int J Oral Maxillofac Implants 1991; 6: 177-185.

32. McGlumphy E A, Campagni WV, Peterson L J. A comparison of the stress transfer characteristics of a dental implant with a rigid or a resilient internal element. J Prosthet Dent 1989; 62: 586-593.

33. Lundgren $D$, Laurell $L$. Biomechanical aspects of fixed bridgework supported by natural teeth and endosseous implants. Periodontology 2000 1994; 4: 23-40.

34. Velasquez-Plata D, Lutonsky J, Oshida Y, Jones R. A close-up look at an implant fracture: a case report. Int J Periodont Rest Dent 2002; 22: 483-491.

35. Cohen S R, Orenstein J H. The use of attachments in combination implant and natural-tooth fixed partial dentures: a technical report. Int J Oral Maxillofac Implants 1994; 9: 230-234. 